\title{
Emergency caesarean section and its sequelae in a tertiary hospital in Niger Delta, Nigeria
}

\author{
Rose Sitonma Iwo-Amah ${ }^{1}$, Felix Chikaike Clement Wekere ${ }^{1,2 *}$, \\ Simeon Chijioke Amadi ${ }^{1}$, Joseph Ngozi Kwosah ${ }^{1}$
}

\begin{abstract}
${ }^{1}$ Department of Obstetrics and Gynaecology, ${ }^{2}$ Department of Community Medicine, Rivers State University Teaching Hospital, Port Harcourt, Nigeria
\end{abstract}

Received: 30 September 2021

Accepted: 28 October 2021

\section{*Correspondence:}

Dr. Felix Chikaike Clement Wekere,

E-mail: fccwekere@yahoo.com

Copyright: ( ) the author(s), publisher and licensee Medip Academy. This is an open-access article distributed under the terms of the Creative Commons Attribution Non-Commercial License, which permits unrestricted non-commercial use, distribution, and reproduction in any medium, provided the original work is properly cited.

\begin{abstract}
Background: Caesarean section (CS) is one of the most common surgical procedure in obstetrics. It involves a surgical incision made through the abdominal and uterine walls to deliver the foetus and placenta after the period of foetal viability.

Methods: This was a cross-sectional study aimed at reviewing emergency caesarean section in Rivers State University Teaching Hospital (RSUTH) over a 5-year period, to determine the prevalence and sequelae. Data were analysed using IBM Statistical Product and Service Solution (SPSS) version 25.0 (Armonk, NY).

Results: During the review period, there were 13516 deliveries and 3699 cases of emergency CS, giving the prevalence of emergency CS as $27.4 \%$ or 274 per 1000 deliveries. Majority (90\%) of the parturient were unbooked. The most common complication in women that had emergency caesarean section was fever $(56.4 \%)$, followed by endometritis (14.7\%), absconding from hospital (8.8\%), urinary tract infection $(7.1 \%)$ and wound infection $(6.1 \%)$. There was a statistically significant association between types of CS and their sequelae, $\chi^{2}=1153.9, \mathrm{p}<0.001,(95 \%$ CI: $0.000,0.000)$. Women that had emergency CS were 101 times more likely to have a complication compared to those that had planned CS.

Conclusions: The rate of emergency caesarean section is high in RSUTH and with more complications compared to planned caesarean section. Booking for antenatal care, early presentation for delivery, birth preparedness and complication readiness will enhance improved maternal and perinatal outcome.
\end{abstract}

Keywords: Caesarean section, Complications, Emergency, Prevalence, RSUTH

\section{INTRODUCTION}

Caesarean delivery has significantly reduced maternal and perinatal morbidity and mortality rates in modern obstetrics. ${ }^{1}$ It is a surgical procedure in which incisions are made through the woman's abdominal wall and uterus after period of foetal viability ( in our setting 28 weeks) to deliver the foetus and placenta. ${ }^{2,3}$ Caesarean section (CS) is necessary when labour is unsafe for either mother or foetus, where labour cannot be induced, when dystocia or fetal problems present significant risks with vaginal delivery, and when an emergency mandates immediate delivery. ${ }^{1,4}$

An emergency caesarean section is a delivery in which decision-to-delivery time is within 30 minutes. . $^{56}$ According to Lucas et al, caesarean section can be classified into four categories of urgency without specific time constraints namely: grade 1-immediate threat to the life of woman or foetus; grade 2- maternal or foetal compromise, which is not immediately life-threatening; grade 3- needing early delivery, but no maternal or fetal compromise; grade 4- at a time suitable for the woman and 
the maternity team. ${ }^{7}$ Grades 1 and 2 were classified as emergency caesarean section in this study.

The outcomes of caesarean deliveries are much better now than in the last century because of better surgical techniques, improved anaesthesia, effective antibiotics, availability of blood and blood products, oxytocic and increased awareness of medico-legal issues. ${ }^{6,8}$ Although there are different categories of CS, in developing countries like Nigeria, $>60 \%$ of cases are emergency CS. These emergency caesarean sections are associated with unfavourable consequences/complications due to lack of adequate preparedness. The problem of poor socioeconomic status of our women, inadequate exposure to formal education, lack of financial empowerment, cultural beliefs that relegate women to the background, and the government's poor funding of the health sector are brought to play. ${ }^{9-11}$ This study was aimed at reviewing emergency caesarean sections over a 5-year period, in Rivers State University Teaching Hospital (RSUTH) to determine its prevalence and sequelae.

\section{METHODS}

The research was carried out at the Rivers State University Teaching Hospital (RSUTH) in Port Harcourt, Nigeria's South-South region. RSUTH was formerly known as Braithwaite Memorial Specialist Hospital and was upgraded to the status of a Teaching Hospital in 2018. ${ }^{12}$ The hospital is owned and funded by the Rivers State Government of Nigeria. It is the Teaching Hospital of the College of Health Sciences, Rivers State University. It is situated in the heart of Port Harcourt, the capital of Rivers State, which has a population of 5,198,716 from the last national census conducted in 2006, making it the 6th most populous state in Nigeria. ${ }^{13}$ RSUTH is a tertiary health facility and receives referrals from both private and public hospitals within the state and neighbouring states like Bayelsa, Imo, Ebonyi, Akwa-Ibom and Delta States.

A study proforma was used to collect data on patient's sociodemographic factors (age, parity, educational status, religion and marital status), types of caesarean section, outcome and sequelae. For this study, Luca's grades 1 and 2 caesarean section were considered as emergency caesarean section. That is, those cases of caesarean section done due to immediate threat to the life of woman or foetus (Grade1) and maternal or foetal compromise, which is not immediately life-threatening (Grade 2). Records of all cases of caesarean sections done in our hospital from January 2015-December 2019 were retrieved and reviewed.

Data were coded and analysed using IBM Statistical Product and Service Solutions (SPSS), version 25.0 Armonk, NY. Categorical variables were summarized in frequencies and percentages. Test of association was carried out using Chi-square test. Level of significance was set at $\mathrm{p}<0.05$. Results were presented in figures and tables as appropriate to the data. Ethical clearance for the study was obtained from Research Committee.

\section{RESULTS}

Over the period of review, there were three thousand six hundred and ninety-nine (3699) cases of emergency caesarean sections, and 13516 deliveries. The rate of emergency caesarean section during the period of review was $27.4 \%$ or 274 per 1000 deliveries (Table 1). Of the 5598 cases of caesarean sections, $3699(66.1 \%)$ were emergency caesarean sections and 1899 (33.9\%) were elective caesarean sections (Figure 1). Of the women that had emergency caesarean section, 3329 (90\%) were unbooked while $370(10 \%)$ were booked patients (Figure 2). Majority of the patients were self-employed (37.4\%), followed by public servants $(18.8 \%)$, business $(18.3 \%)$ (Figure 3).

Table 1: Yearly trend in the rate of emergency caesarean section in RSUTH.

\begin{tabular}{|c|c|c|c|}
\hline Year & $\begin{array}{l}\text { Total number } \\
\text { of emergency } \\
\text { C sections }\end{array}$ & $\begin{array}{l}\text { Total } \\
\text { number of } \\
\text { deliveries }\end{array}$ & $\begin{array}{l}\text { Emergency C } \\
\text { section rate }\end{array}$ \\
\hline 2015 & 706 & 3020 & 23.37 \\
\hline 2016 & 760 & 3495 & 21.74 \\
\hline 2017 & 750 & 2747 & 27.30 \\
\hline 2018 & 844 & 2294 & 36.79 \\
\hline 2019 & 639 & 1960 & 32.60 \\
\hline Total & 3699 & 13516 & 27.38 \\
\hline
\end{tabular}

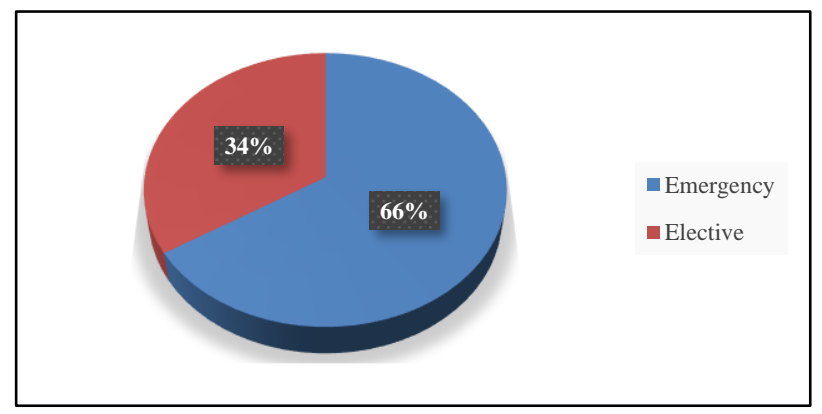

Figure 1: Distribution of types of caesarean section.

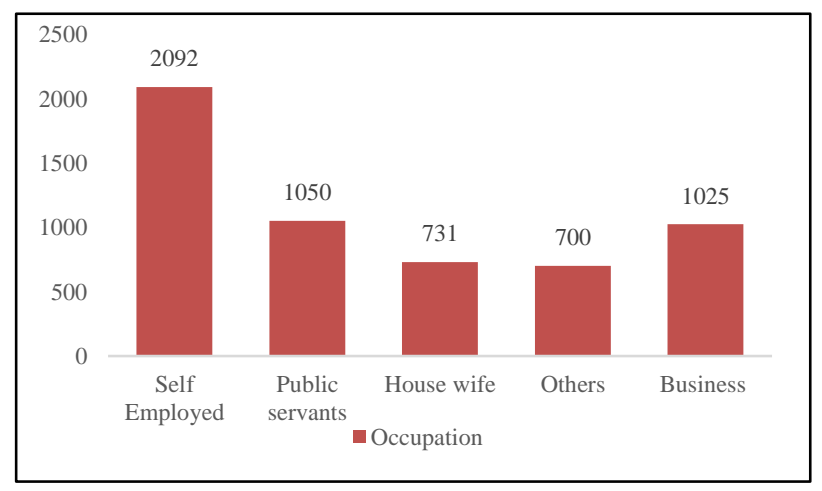

Figure 2: Occupation of the participants. 


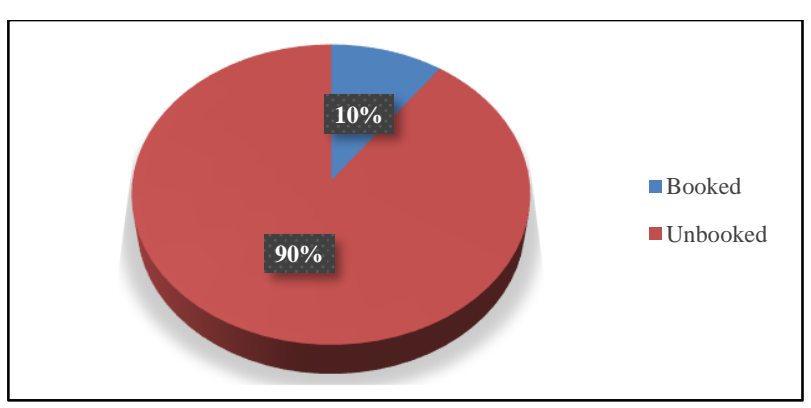

Figure 3: Booking status of women that had emergency caesarean section in RSUTH.

Of 1666 women that had complications following caesarean section, $1651(99.1 \%)$ were from emergency CS while 15 (0.9) were from elective CS (Table 2). There was a statistically significant association between the types of caesarean sections and complications $\chi^{2}=1153.9$, $\mathrm{p}<0.001$; [95\% Confidence interval (CI): 0.000, 0.000)]; odds ratio $(\mathrm{OR})=101.3$.

Table 2: Association between type of caesarean section and complications.

\begin{tabular}{|lllll|}
\hline Type of CS* & \multicolumn{2}{l}{ Complications } & Total & $\begin{array}{l}\mathbf{O R}^{+} \\
(\mathbf{9 5} \% \mathbf{C I})^{\#}\end{array}$ \\
\hline & Yes & No & & \\
\hline Emergency & 1651 & 2048 & 3699 & $101.25(60.67$, \\
CS & $(44.6)$ & $(55.4)$ & $(100)$ & $168.99)$ \\
\hline Elective & 15 & 1884 & 1899 & \\
CS & $(0.8)$ & $(99.2)$ & $(100)$ & \\
\hline \multirow{2}{*}{ Total } & 1666 & 3932 & 5598 & \\
& $(29.8)$ & $(70.2)$ & $(100)$ & \\
\hline
\end{tabular}

$\chi^{2}=1153.91 ; \mathrm{df}=1, \mathrm{p}<0.001 \quad \# 95 \%$ Confidence interval,

${ }^{*}$ Caesarean section, ${ }^{+}$Odds ratio

Table 3: Outcome/sequelae of caesarean section in RSUTH.

\begin{tabular}{|lll|}
\hline Complications & $\begin{array}{l}\text { Emergency } \\
\text { C-sec }(\%)\end{array}$ & $\begin{array}{l}\text { Elective } \\
\text { C-sec (\%) }\end{array}$ \\
\hline Fever & $958(56.4)$ & $7(36.8)$ \\
\hline Postpartum haemorrhage & $8(0.5)$ & $2(10.5)$ \\
\hline Endometritis & $250(14.7)$ & $5(26.3)$ \\
\hline Wound infection & $104(6.1)$ & $2(10.5)$ \\
\hline Aspiration & $1(0.1)$ & 0 \\
\hline Urinary tract infection & $120(7.1)$ & $1(5.3)$ \\
\hline Thrombophlebitis & $5(0.3)$ & 0 \\
\hline Pulmonary embolism & $3(0.2)$ & $1(5.3)$ \\
\hline Injury to internal organs & $3(0.2)$ & 0 \\
\hline Caesarean hysterectomy & $3(0.2)$ & 0 \\
\hline Injury to infant & $5(0.3)$ & 0 \\
\hline Postpartum depression & $12(0.7)$ & 0 \\
\hline Pelvic abscess & $8(0.5)$ & 0 \\
\hline Absconding from hospital & $150(8.8)$ & 0 \\
\hline Maternal death & $10(0.6)$ & $1(5.3)$ \\
\hline Perinatal death & $58(3.4)$ & 0 \\
\hline Total & 1698 & 19 \\
\hline
\end{tabular}

From this study, the most common complication in women that had caesarean section was fever $(56.4 \%)$, followed by endometritis (14.7\%), absconding from hospital $(8.8 \%)$, urinary tract infection $(7.1 \%)$ and wound infection $(6.1 \%)$ (Table 3).

\section{DISCUSSION}

The rate of emergency caesarean section in Rivers State University Teaching Hospital over the period reviewed was $27.4 \%$ or 274 per 1000 deliveries. This finding corroborates those of previous studies, but lower than $78.2 \%$ and $84.7 \%$ reported in Calabar, Sokoto Nigeria, and $70 \%$ in Ghana respectively. ${ }^{6,14-16}$ Although differences in the number of deliveries as well as number of cases could account for the regional differences, the finding of high rate of emergency CS in present study, may be due to the increased number of cases referred to the hospital from peripheral health centres; and delay in decision making by the parturient and their relatives. Additionally, all cases of caesarean section in primary health centres, some secondary health centres and catchment areas are often referred to RSUTH for expert management. Furthermore, most women were unwilling to have abdominal delivery. As such, they gave consent for CS only when there was glaring evidence that the woman or her baby may die, buttressing the high aversion to caesarean section in our environment. This is in keeping with findings of previous studies. ${ }^{14,17,18}$

Most of the emergency cases (90\%) were among unbooked mothers, who were rushed to our facility when it was obvious that there was a high risk of losing their lives or that of their babies. This finding is consistent with that of previous study on emergency caesarean section; but contrary to the finding of a higher rate of emergency CS among booked mothers in previous studies in Nigeria. ${ }^{6,19,20}$ Our finding is not surprising since most of these women did not receive antenatal care due to ignorance, illiteracy and poverty. They were being referred to our facility from traditional birth attendants' home, health centres, or by self-referral. More so, in this study urgent caesarean section (decision-to-delivery time: 30 minutes to 8 hours) was included as emergency CS because other factors like refusal to give consent for surgery on time, waiting for their husband, or whoever is to foot the bill before signing the consent form, adequate time to resuscitate patient before surgery, and availability of blood, waiting for an anaesthetist or neonatologist, all caused delays that were beyond 30 minutes.

In present study, complications arising from CS were more among women that had emergency CS compared with elective caesarean section. This finding is in keeping with findings from other studies. ${ }^{6,21}$ Late presentation of parturient with complicated labour that had gone beyond 24 hours could account for a higher rate of complications observed among women that had emergency caesarean section. The commonest complication in present study was fever (pyrexia). Others were endometritis, absconding 
from hospital, urinary tract infection, wound infection. This is similar to the findings of previous study in Nigeria. ${ }^{21}$ Prolonged labour and multiple vaginal examinations in the referring centre could account for the above complications. Also, compliance with postoperative medication was a problem with some of these emergency cases because of financial constraint. This may also account for the cases of infections observed from the study. The cases of caesarean hysterectomy were due to uncontrollable haemorrhage, secondary to morbidly adherent placenta. Although the welfare department of the hospital assisted as much as they could, abandonment of these patients by their relatives led to a lot of them absconding without settling outstanding hospital bills. Most of these unfavourable outcomes would have been prevented if CS was planned, instead of being an emergency procedure.

\section{CONCLUSION}

The rate of emergency caesarean section is high in our centre. Complications following CS was more among emergency cases compared with elective CS. Therefore, booking for antenatal care in the hospital with skilled birth attendant, early referral of $\mathrm{CS}$ cases and adequate preparation for CS would enhance good foeto-maternal outcome.

The outcomes of elective caesarean sections are much better than that of emergency $\mathrm{C}$-section because of adequate preparedness. This needs to be inculcated in our women. Since most of them cannot make informed decisions about their health and well-being for fear of being reprimanded by their husbands or in-laws. They should be encouraged to attend antenatal clinics where they can have adequate obstetric care participate in beneficial lessons on maternal and new-born care are taught as well as different contraceptive methods. There needs to be increased awareness on caesarean delivery as well as the advantages of having a planned CS, instead of an emergency CS. The government needs to provide more funding to the health sector, to make available materials for women who cannot afford healthcare.

\section{ACKNOWLEDGMENTS}

We wish to thank the staff of the department of Obstetrics and Gynaecology, Rivers State University Teaching Hospital for their support during the conduct of this research.

Funding: No funding sources Conflict of interest: None declared

Ethical approval: The study was approved by the Institutional Ethics Committee

\section{REFERENCES}

1. Danforth DN. Danforth's obstetrics and gynecology. 10th edn. Lippincott Williams and Wilkins; 2008.
2. Gelaw KA, Aweke AM, Astawesegn FH, Demissie BW, Zeleke LB. Surgical site infection and its associated factors following cesarean section: a cross sectional study from a public hospital in Ethiopia. Patient Safety Surg. 2017;11(1):1-7.

3. Kwawukume E, Laryen H. Caesarean section. In: Kwawukume EY, Ekele BA, Danso KA, Emuveyan E, eds. Comprehensive obstetrics in the Tropics. 2nd edn. Accra: Asante and Hittscher Printing Press Ltd; 2015:205- 414.

4. Tsegaye H, Desalegne B, Wassihun B, Bante A. Prevalence and associated factors of caesarean section in Addis Ababa hospitals, Ethiopia. Pan Afr Med J. 2019;34.

5. Leung TY, Lao TT. Timing of caesarean section according to urgency. Best Pract Res Clin Obstet Gynaecol. 2013;27(2):251-67.

6. Idikwu OG, Onazi O, Anzaku AS, V F. Emergency caesarean deliveries: Analysis of 592 cases in federal medical centre Keffi, North Central Nigeria. Int J Clin Obstet Gynaecol. 2018;2(5):100-3.

7. Lucas DN, Yentis SM, Kinsella SM, Holdcroft A, May AE, Wee M, et al Urgency of caesarean section: a new classification. J Royal Soc Med. 2000;93(7):346-50.

8. Jaiyesimi RA, Ojo OE, Awe AF. Caesarean delivery and peripartum hysterectomy. Contemp Obstet Gynecol Develop Countries. 2021:203-21.

9. Gunn JK, Ehiri JE, Jacobs ET, Ernst KC, Pettygrove $\mathrm{S}$, Center KE, et al. Prevalence of Caesarean sections in Enugu, southeast Nigeria: Analysis of data from the Healthy Beginning Initiative. PloS One. 2017;12(3):e0174369.

10. Ezeonu PO, Ekwedigwe KC, Isikhuemen ME, Eliboh MO, Onoh RC, Lawani LO, et al. Perception of caesarean section among pregnant women in a rural missionary hospital. Adv Reprod Sci. 2017;5(3):33-8.

11. Ajayi AI. Inequalities in access to birth by caesarean section in the context of user fee exemption for maternal health services in southwest and north central Nigeria. Int Health. 2020.

12. Wekere FCC, Kua PL, Kalio DG, Iwo-Amah RS. Assessing the awareness, ownership and utilization of insecticide-treated bed nets amongst antenatal clinic attendees: a tertiary hospital-based study. Asian Res J Gynaecol Obstet. 2020:21-9.

13. National Population Commision (NPC). Rivers State, Nigeria Population statistics. 2006. Available from: https://www.citypopulation.de/php/nigeriaadmin.php?adm1id=NGA033. Accessed on 8 September 2021.

14. Osonwa O, Eko J, Ekeng P. Trends in caesarean section at Calabar general Hospital, Cross river state, Nigeria. Eur J Biol Med Sci Res. 2016;4(1):1-5.

15. Nwobodo E, Isah A, Panti A. Elective caesarean section in a tertiary hospital in Sokoto, north western Nigeria. Niger Med J. 2011;52(4):263.

16. Gulati D, Hjelde GI. Indications for Cesarean Sections at Korle Bu Teaching Hospital, Ghana. 2012. 
17. Prah J, Kudom A, Afrifa A, Abdulai M, Sirikyi I, Abu E. Caesarean section in a primary health facility in Ghana: clinical indications and feto-maternal outcomes. J Public Health Afr. 2017;8(2).

18. Akinola OI, Fabamwo AO, Tayo AO, Rabiu KA, Oshodi YA, Alokha ME. Caesarean section- an appraisal of some predictive factors in Lagos Nigeria. BMC Pregnancy Childbirth. 2014;14(1):1-6.

19. Osegi N, Makinde OI. Towards optimizing caesarean section: a five-year review of caesarean sections at a Southern Nigeria hospital. Int J Reprod Contracept Obstet Gynecol. 2020;9(1):205-11.
20. Daniel C, Singh S. Caesarean delivery: an experience from a tertiary institution in north western Nigeria. Niger J Clin Pract. 2016;19(1):18-24.

21. Chukwu E, Ekeh C, Haruna H, Chia T, Fiase T. Prevalence of caesarean section deliveries among primigravidae in general hospital Gboko, Benue State, Nigeria. Int J Clin Pediatr Surg. 2017;3(3):25-9.

Cite this article as: Iwo-Amah RS, Wekere FCC, Amadi SC, Kwosah JN. Emergency caesarean section and its sequelae in a tertiary hospital in Niger Delta, Nigeria. Int J Reprod Contracept Obstet Gynecol 2021;10:4372-6. 